
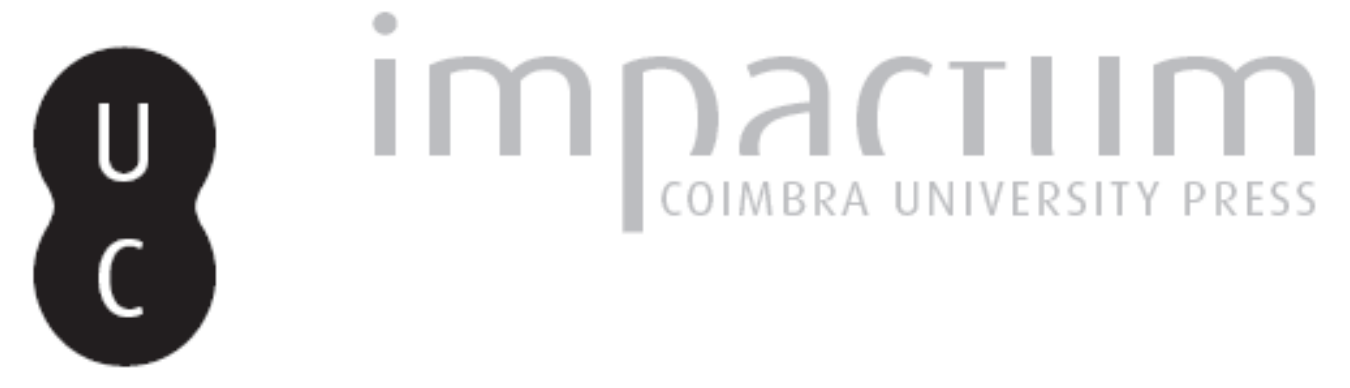

\title{
A hegemonia de Atenas
}

Autor(es): $\quad$ Ferreira, José Ribeiro

Publicado por: Imprensa da Universidade de Coimbra

URL persistente:

URl:http://hdl.handle.net/10316.2/45566

DOI:

DOI:https://dx.doi.org/10.14195/1647-8657_28_2

Accessed : $\quad$ 26-Apr-2023 11:06:01

A navegação consulta e descarregamento dos títulos inseridos nas Bibliotecas Digitais UC Digitalis, UC Pombalina e UC Impactum, pressupõem a aceitação plena e sem reservas dos Termos e Condições de Uso destas Bibliotecas Digitais, disponíveis em https://digitalis.uc.pt/pt-pt/termos.

Conforme exposto nos referidos Termos e Condições de Uso, o descarregamento de títulos de acesso restrito requer uma licença válida de autorização devendo o utilizador aceder ao(s) documento(s) a partir de um endereço de IP da instituição detentora da supramencionada licença.

Ao utilizador é apenas permitido o descarregamento para uso pessoal, pelo que o emprego do(s) título(s) descarregado(s) para outro fim, designadamente comercial, carece de autorização do respetivo autor ou editor da obra.

Na medida em que todas as obras da UC Digitalis se encontram protegidas pelo Código do Direito de Autor e Direitos Conexos e demais legislação aplicável, toda a cópia, parcial ou total, deste documento, nos casos em que é legalmente admitida, deverá conter ou fazer-se acompanhar por este aviso.

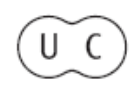


FACULDADE DE LETRAS

INSTITUTO DE ARQUEOLOGIA

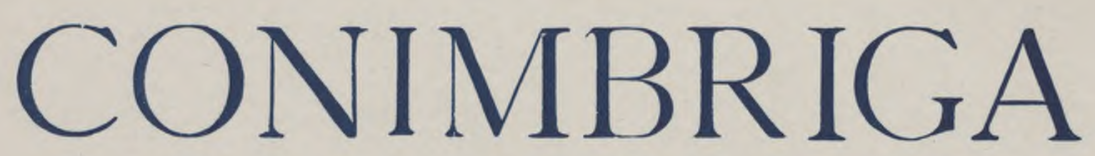

VOLUME XXVIII

UNIVERSIDADE DE COIMBRA

1989 


\section{JOSÉ RIBEIRO FERREIRA}

Professor associado da Faculdade de Letras da Universidade de Coimbra.

A HEGEMONIA DE ATENAS

«Conimbriga», XXVIII (1989), p. 33-51

RESU Mo: Começa por salientar a política naval de Temístocles que conduz à construção de uma poderosa frota de guerra. É essa força naval que inflige aos Persas pesada derrota na batalha de Salamina (480 a. C.). O autor analisa depois a formação da Simaquia de Delos (477 a. C), que Heródoto considera uma continuação da aliança grega contra os Persas, criada em 480 a. C.; sublinha que, nascida de início de uma adesão voluntária dos seus membros, se transforma progressivamente no império de Atenas sobre os aliados e põe em realce a importância dos tributos pagos por esses aliados para a consolidação da democracia ateniense. Conclui, portanto, que, subjacentes aos conhecidos acontecimentos históricos das Guerras Pérsicas, da criação da Simaquia de Delos e da consequente consolidação do império ateniense, se detectam interrelações entre sistema político e situação económica e social, determinantes para o estabelecimento definitivo de uma forma de governo - o da democracia ateniense - que era também, ao mesmo tempo, de um estilo de vida.

SUMmary: In the first place the author emphasizes Themistocles' naval policy, which led to an energetic shipbuilding programme. As a result the Persians were entirely defeated at the naval battle of Salamis (480 B.C) by the greatly increased Greek fleet. Secondly Ribeiro Ferreira studies the Delian league, regarded by Herodotus as a continuation of the Greek aliance (since 480 B.C.) against the Persian menace. Thirdly we are told about the progressive decline of the Athens' supremacy over its allies. The author also underlines the importance of the tributes paid by those allies to the affirmation of the Athenian democracy. As a matter of fact, underlying those well known historical events, there was a strong interrelationshisp between the political system and the economic and social status, which was determinant for the definitive establishing not only of a form of government - that of the Athenian democracy —, but also, at the same time, of a style of living. 
(Página deixada propositadamente em branco) 


\section{A HEGEMONIA DE ATENAS*}

No período que se segue à invasão de Xerxes em 480 e vai até aos inícios da Guerra do Peloponeso, em 431, Atenas torna-se uma cidade poderosa e cada vez mais interveniente no contexto do mundo grego, um pouco em consequência da sua acção nas Guerras Pérsicas e sobretudo com base na Simaquia de Delos, criada em 477. Esta começa por ser uma aliança voluntária das cidades do Egeu e da Ásia Menor com Atenas, para se precaverem contra possíveis arremetidas persas futuras $\left.{ }^{1}{ }^{1}\right)$. Heródoto apresenta-a mesmo como uma consequência dessas Guerras e a hegemonia de Atenas como uma conclusão natural e lógica do papel desempenhado pela cidade nesse conflito ${ }^{2}$ ).

(*) Trabalho preparado no âmbito do Projecto «Estudos de Cultura Clássica» do Centro de Estudos Clássicos e Humanísticos da Universidade de Coimbra (I.N.I.C.).

(!) Sobre a Simaquia de Delos é extensa a bibliografìa. Vide entre outros, N. G. L. Hаммолd, «The Origins and the Nature of the Athenian Alliance of 478/477 B.C.», JHS 87 (1967) 41-61 (= Studies in Greek History, Oxford, 1973, p. 311-345, onde tem o título «The Organization of the Athenian Alliance against Persia»); D. Blackman, «The Athenian Navy and Allied Naval Contributions in the Pentekontaetia», GRBS 10 (1969) 179 sqq.; C. M. Bowra, Periclean Athens, London, 1971, p. 26-36; M. I. Finley, Democracy, Ancient and Modern, London, 1973, p. 43-50; Russel Meigs, The Athenian Empire, Oxford, 1972, repr. 1975; Éd. WILL, Le monde grec et VOrient. I - Le Ve siècle, Paris, 1972, p. 130-218; S. Hornblower, The Greek World 479-323 B.C., London, 1983, p. 15-47; M. I. FinLEY, «The Fifth-Century Athenian Empire: a balance-sheet», in P. D. A. GARNSEY and C. R. Whitt aker (ead.), Imperialism in Ancient World, Cambridge, 1978, p. 103 sqq. (= Economy and Society in Ancient Greece, London, 1981, p. 41-61).

(2) Cf. 8.3 e 9. 90-122. Sobre o assunto e para um comentário aos passos, vide H. R. IMMERWAhr, Form and Thought in Herodotus, Cleveland, 1966, p. 216-223; J. Ribeiro Ferreira, Hélade e Helenos, I - Génese e evolução de um conceito, Coimbra, 1983, p. 348-350. 
Como é do conhecimento geral, afastado o perigo do ataque persa de 490, após a batalha de Maratona, receava-se uma segunda invasão, temor que se agrava com as informações alarmantes que por volta de 483 começam a chegar: na Pérsia realizavam-se então preparativos militares e não seria difícil prever a sua finalidade.

Temístocles, que na altura pontificava em Atenas, terá reconhecido que só uma frota poderosa conseguiria conter o ataque persa iminente, além de constituir ainda um meio para enfraquecer as classes elevadas e um instrumento para resolver o eterno conflito com Egina. Pensava ele que a cidade, com um bom abrigo natural no Pireu e aberta para o mar, só podia aproveitar-se verdadeiramente da sua situação geográfica se possuísse uma frota de guerra. Em sua opinião esse era o caminho que havia de trazer a Atenas poder e riqueza; apenas o domínio do mar a tornaria uma grande potência no mundo grego. O Egeu, caminho de comércio e de trocas consideráveis e vitais, vivia sob a ameaça constante da pirataria, sem nenhum poder que tornasse as suas rotas sem perigo. Só uma frota forte poderia tornar esse mar seguro e trazer o proveito ao país que realizasse tal tarefa.

Temístocles conseguiu progressivamente convencer os concidadãos das suas razões e das vantagens da política que propunha. Por essa altura o porto do Pireu foi preparado para receber uma frota de trirremes. Os meios para as construir surgiram-lhe na descoberta, em 483, nas minas do Láurion, de um novo filão de prata de grande riqueza que produzia para o Estado não menos de cem talentos - a jazida de Maroneia( $\left.{ }^{3}\right)$. A pòlis concede a exploração dessas minas a particulares, mediante $\mathrm{o}$ pagamento de um quinto do minério extraído. Em vez de distribuir pelos cidadãos esses recursos, como até aí se fazia, Temístocles submete à Assembleia uma proposta - e consegue a aprovação, graças ao seu prestígio - , para empregar esses rendimentos na

(3) Vide J. A. Labarbe, La loi navale de Themistocle, Paris, 1957; V. Ehrenberg, From Solon to Socrates, London, ${ }^{2} 1973$, repr. 1976, p. 148; A. J. Podlecki, The Life of Themistocles, Montreal, 1975, p. 201-204. 
construção de barcos de guerra, as trirremes $\left({ }^{4}\right)$. Temístocles utiliza o forte argumento do poder naval de Egina, cujos barcos impunham na altura a sua presença no Pireu. Situada no Golfo Sarónico, apenas a algumas milhas das costas da Ática, Atenas vivia em constantes lutas com ela, sem resultados positivos, já que a inexistência de uma frota eficaz tornava impossível subjugá-la ${ }^{5}$ ). Embora o argumento utilizado fosse esse, Temístocles, como acentua Ehrenberg, pensava naturalmente nos Persas $\left(^{6}\right)$.

Construídos os barcos, era necessário tripulá-los e conseguir homens e remadores que os manobrassem, e o fizessem com um alto grau de eficácia. Tal desiderato só se atingia mediante treino conjunto e prolongado.

Dessa missão ficam incumbidos os tetas, sobretudo os que não tinham quaisquer meios de fortuna, que por isso nunca haviam participado no exército - recordo que na Grécia era o próprio cidadão-soldado quem fornecia o seu armamento $\left({ }^{7}\right)$. Era mais fácil recrutar os homens nos sectores mais pobres que não estavam ligados à terra ou à oficina de algum mester.

A criação da frota implica o aparecimento de um sector estreitamente dependente do Estado no soldo e na subsistência.

Deste modo se forma uma força naval eficiente e treinada que vai dominar no Egeu até ao fim do século $\mathrm{v}$ e que, quando da segunda invasão persa em 480, estava pronta a actuar.

(4) Cf. Hdt. 7.144; Thuc. 1.14.3.

C. M. Bowra, Periclean Athens, p. 20, fala em 100 trirremes; V. Ehrenberg, From Solon to Socrates, p. 148, sugere 200, embora dubitativamente.

$\left.{ }^{5}\right)$ Por volta de 488 Atenas entra mais uma vez em guerra com Egina, para apoiar um levantamento democrático naquela ilha. Precisou contudo de alugar barcos a Corinto, por um preço nominal. A continuação da guerra ofereceu um pretexto e um argumento forte à política naval de Temístocles. Vide A. J. Podlecki, The Life of Themistocles, p. 58 e 69.

$\left(^{6}\right)$ From Solon to Socrates, p. 148.

(7) Vide A. M. Snodgrass, «The Hoplite Reform and History», JHS 85 (1965) 114-115; W. K. Pritchetт, Ancient Greek Military Practices, I Part. California Univ. Press., 1971, caps. 1 e 2. 
Ante a perspectiva dessa nova invasão, os Gregos procuram uma frente unida. Realiza-se um congresso dos Helenos que se decide por um estabelecimento de tréguas entre eles e por uma aliança para enfrentarem em conjunto os Persas; pelo envio de espiões à Pérsia e de mensageiros a Gélon de Siracusa (cf. Hdt. 7.145 sqq.).

Temístocles, para que a cidade se apresentasse unida, propõe a amnistia dos elementos ostracizados. Soluciona sagazmente a terrível situação terrestre, transportando a população para Salamina e outros lugares, e colocou a esperança de vitória na frota que preparara. Teve, no entanto, dificuldade em convencer os outros Gregos da eficácia da tática que propunha e em vencer o seu medo em ficarem à espera no mar fechado entre Salamina e o continente; preferiam recolher-se no Peloponeso erguendo um muro no istmo de Corinto $\left({ }^{8}\right)$.

De qualquer modo, um pouco sob pressão, os outros Gregos acabam por aceitar a sua estratégia, desde que comandados por Esparta. Atenas acede, e Temístocles, como é sabido, por meio de um engano, levou os Persas a atacar em lugar desfavorável e consegue uma vitória retumbante, confirmada cerca de um ano depois, em 479, na batalha terrestre de Plateias. Os barcos persas fogem para o Egeu, onde também um ano mais tarde são novamente vencidos em Mícale $\left({ }^{9}\right)$.

Os barcos haviam ficado prontos e preparados a tempo de enfrentarem a invasão de 480. A sua actuação mudou a história de Atenas, a da Grécia e até a da Europa $\left({ }^{10}\right)$.

$\left.{ }^{8}\right)$ Vide A. R. Burn, Persia and the Greeks. Defense of the West 546-478 B.C., London, 1962, p. 432-433; G. Hignet T, Xerxes' Invasion of Greece, Oxford, 1963, p. 192 e 201; P. GreEN, The Years of Salamis: 480-479 B.C., London, 1970, p. 157-158 e 168-172; J. Ribeiro Fereira, Hélade e Helenos, p. 347-348.

(9) Sobre as batalhas de Salamina, de Plateias e de Mícale vide, N. G. L. наммому, «The Battle of Salamis», JHS 76 (1956), p. 32-54 (== Studies in Greek History, p. 251-310); A. R. Bu RN, Persia and the Greeks, p. 400-402, 427-475, 508-546 e 546-551; C. Hignet T, Xerxes' Invasion of Greece, Oxford, 1963, p. 149-344; P. Gre EN, The Year of Salamis. 480-479 B.C., London, 1970.

$\left.{ }^{10}\right)$ A confiança que essa vitória trouxe a toda a Grécia foi vital para a evolução futura. Decorria o início do século Vea Hélade ainda não havia chegado ao apogeu do período clássico nem produzira as suas mais importantes 
A frota, dirigida por Temistocles, um comandante hábil e dotado de grande visão, dera a vitória aos Gregos e libertara-os da ameaça dos Persas. O futuro da cidade estava no mar. Era também mais uma etapa do crescimento democrático, a que temos de ligar o nome desse dirigente. A via para uma mais avançada democracia caminha em Atenas a par da política naval (11).

Homens do mar, esses vencedores do Artemisio, de Salamina e de Mícale diferiam social e economicamente dos hoplitas e dos cavaleiros, uns e outros ligados à terra e com a obrigação de custearem os seus equipamentos e montadas. Os marinheiros, pelo contrário, eram assalariados da pòlis e não tinham outro meio de subsistência que não fosse o soldo recebido pela função exercida na frota. Os cidadãos mais pobres, como é lógico em consequência de constituírem peças necessárias, têm nessas vitórias papel de primeiro plano e saem delas prestigiados e na qualidade de heróis. As guerras cimentaram o regime em Atenas e criaram ainda as condições para novo e maior desenvolvimento dessa democracia. Desse modo as classes não hoplíticas ficam com papel decisivo na pòlis.

A defesa dos interesses da cidade e a sua salvação passam cada vez mais por esses tetas sem recursos que até aí estavam excluídos de todo o poder que não fosse a participação na Assembleia e na Helieia. Ganham consciência de si mesmos, do que representavam na pòlis e, à medida que tal acontecia, passavam a exercer uma maior influência na Assembleia ( $\left.{ }^{12}\right)$.

É curioso observar que a marinha foi sempre acérrima defensora da democracia em Atenas e que, na ocasião do golpe oligárquico de 411, foi ela quem repôs a legalidade democrática ( $\left.{ }^{13}\right)$.

realizações culturais. Dado que a cultura ociedental é profunda devedora da grega, não será difícil imaginar que a nossa cultura seria hoje bem diferente, caso a vitória em Salamina tivesse pendido para o lado dos Persas.

(u) Vide E HR E n E R G, From Solon to Socrates, p. 145-146.

(12) Sobre a importância da marinha em Atenas, vide N. G. L. наммомd, A History of Greece to 322 B.C., Oxford, 31986, repr. 1987, p. 324-332; F. Арсок and D. J. Mosley, Diplomacy m Ancient Greece, London, 1975, p. 23-29.

(13) Vide Éd. Will, $\boldsymbol{L}^{\boldsymbol{e}}$ Ve siècle, p. 372 sqq.; Gl. Mosse, «Le rôle de l'armée dans la révolution de 411 à Athènes», $R H 231$ (1964), 1 sqq. ; R. SEALEY, 
$\mathrm{Na}$ sequência da retirada dos Persas, após as batalhas de Salamina e de Plateias, os aliados gregos, muitos deles com posições vulneráveis no caso de nova investida, temiam uma terceira invasão. Decidiram, por isso, aproveitar as vitórias para libertar o resto da Hélade e obrigar os Persas a confinarem-se às suas fronteiras. O rei espartano Pausânias, que comandava as forças aliadas, defraudou contudo estas esperanças e, acampado em Bizâncio, manifestava deferência pelos principais chefes persas e arrogância com os Gregos. A desconfiança que tai actuação causou foi de graves consequências para Esparta. Os aliados retiram-lhe o comando das forças, e, no inverno de 478/477, com surpreendente unanimidade, pedem a Atenas que o assuma. Esta, como é evidente, aceita-o de imediato. Os Lacedemónios abandonam as operações e com ela boa parte dos seus antigos aliados na Simaquia do Peloponeso. Os Estados marítimos do Egeu reuniram-se à volta de Atenas para se defenderem e libertarem esse mar da influência persa $\left({ }^{14}\right)$. Assim surge em 477 a Simaquia de Delos, como se fora a continuação da aliança de 480, criada pelos Helenos para fazerem frente aos Persas.

Constituía de início uma aliança naval e, dos membros que a integravam, Atenas era a única potência terrestre. Os restantes eram estados marítimos que bordejavam ou pertenciam ao Egeu. Além de Atenas, dela faziam parte, portanto, as cidades gregas da costa oeste da Ásia Menor; considerável número das cidades da Propôntida, de grande importância estratégica; a Eubeia, com a única excepção da cidade de Caristo, e todas as ilhas do Egeu, salvo Melos, Tera e Creta. Dominava assim esse mar e controlava ainda a ampla e rica ilha de Chipre e a entrada para a costa sul da Ásia Menor. A Simaquia visava manter a ofensiva contra a Pérsia e, através do domínio do Egeu, superintender na política externa grega. Até

«The Revolution of 411 B.G., in Essays in Greek Politics, New York, 1967, p. Ill sqq.

(14) Sobre a origem da Simaquia de Delos vide R. SEALEy, «The Origin of the Delian League», in Ancient Society and Institutions, Studies presented to Victor Ehrenberg, Oxford, 1966, p. 233-255; R. MEIgGs, The Athenian Empire, p. 459-464. 
certo ponto conseguiu esse objectivo. Da sua organização fora encarregado Aristides, membro de uma família nobre e general experimentado, irreconciliável inimigo da Pérsia e sobretudo um homem que tinha a fama de justo e, portanto, perfeitamente talhado para a tarefa de construir uma aliança, em bases equitativas. Para centro administrativo foi escolhida a pequena ilha de Delos, tradicional santuário de Apoio e lugar em que os Ionios, desde recuados tempos, se reuniam (15). No meio do Egeu, oferecia uma posição neutral, era de fácil defesa e, devido à sua pequenez, não oferecia perigo pela sua política e interesses.

Para atingir os seus objectivos, a Simaquia necessitava de constituir e manter uma frota aliada, para a qual os membros deviam contribuir com barcos e com dinheiro, ou apenas com numerário. Alguns dos Estados membros eram pequenos e pobres e preferiram contribuir apenas em moeda. Aristides fixou a soma total em 460 talentos (cf. Thuc. 1. 96), metade paga em dinheiro e a outra em barcos; fez um cálculo meticuloso das possibilidades de cada pòlis e repartiu essa soma proporcionalmente pelos vários membros. Os que contribuíam em dinheiro formavam de longe o grupo mais numeroso. Mesmo Estados grandes e poderosos, alguns deles, preferiam este sistema que evitava aos seus cidadãos a prestação de serviço militar fora do seu território ( $\left.{ }^{16}\right)$. Os pagamentos deviam efectuar-se uma vez por ano no tesouro comum, em Delos. Recebiam os contributos dez funcionários, chamados

(15) Os versos 146-155 do Hino Homérico a Apoio referem-se a um festival iònico que aí se realizava. Como a parte do hino que integra os versos deve datar do séc. VIII, pelo menos já nessa data a ilha era centro de uma reunião de Ionios. Vide H. W. Parke, Greek Oracles, London, 1967, p. 34 sqq. (sobretudo 38).

${ }^{(16)}$ Sobre os quantitativos dos impostos da Simaquia, quer em barcos quer em dinheiro, vide R. Me IG gs, The Athenian Empire, p. 50-67.

Para a dificuldade levantada pelo passo de Tucídides, devido à cifra relativamente volumosa aí referida que, de ceito modo, contrasta com os números mais baixos fornecidos pelas listas de tributos mais recentes, vide, A. W. Gомме, A Historical Commentary on Thucydides, I, Oxford, 1945, p. 273-280, ad. loe.; R. Meiggs, op. citp. 44 sqq. ; P. J. Rhodes, The Athenian Empire, Oxford, 1985, p. 5-8. 
Helenotamias «tesoureiros dos Helenos», que, apesar do nome, eram todos Atenienses $\left({ }^{17}\right)$.

A Simaquia vai ser um instrumento do imperalismo ateniense, mas vem assentar também a democracia em pilares mais sólidos. Segundo Vidal-Naquet, um aspecto da história de Atenas é o avanço de mãos dadas da democracia e do império marítimo (18). Era ela que ditava as leis na organização. No Conselho da aliança, que se reunia em Delos, controlava os votos, não só por ser a pólis mais poderosa, mas porque os pequenos Estados, que detinham apenas um voto, se uniam a ela para se precaverem contra os outros membros poderosos que tentavam intimidá-los e de quem tinham receio.

Sob a hegemonia ateniense, essa Simaquia em menos de dez anos atingiu os seus objectivos. Os Persas tinham desaparecido do Egeu e recolhido ao interior das fronteiras. As ilhas dessa parte do Mediterrâneo e a Grécia Asiática sentiam-se de novo livres; o que isso representava está bem explícito num estásimo (vv. 585-594) dos Persas de Esquilo, levado à cena pouco depois de afastada a invasão de Xerxes:

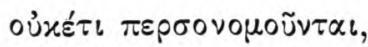

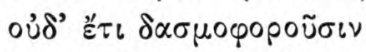

$$
\begin{aligned}
& \delta \varepsilon \sigma \pi 0 \sigma u ́ v 0 เ \sigma L \nu \alpha \dot{\alpha} \alpha \dot{\gamma} \gamma \alpha u \zeta \text {, }
\end{aligned}
$$

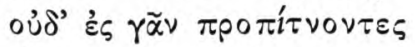

$$
\begin{aligned}
& \ddot{\alpha} \zeta 0 \vee \tau \alpha \iota, \beta \alpha \sigma i \lambda \varepsilon i \alpha
\end{aligned}
$$

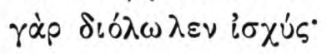

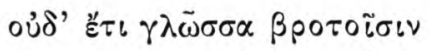

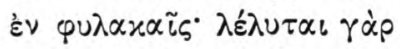

$$
\begin{aligned}
& \lambda \alpha \grave{s} \varepsilon \dot{\varepsilon} \lambda \varepsilon \dot{v} \theta \varepsilon \rho \alpha \beta \alpha \dot{\alpha} \varepsilon \varepsilon \nu,
\end{aligned}
$$

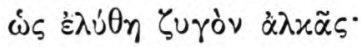

(17) Sobre os Helenotamias, vide A. G. Woodhead, «The lnstitution of the Hellenotamiae», JHS 79 (1959), 149-152; R. Meiggs, The Athenian Empire, cit., p. 44 e 234-238.

$\left.{ }^{18}\right)$ «Tradition de la démocratie grecque», in M. I. FINLEY, Dèmocratie antiqúe et démocratie moderne (trad. franc.), Paris, 1976, p. 39.

Conimbriga, 28 (1989), 33-51 
Não mais se obedecerá à lei dos Persas, não mais se pagará tributo por imposição do soberano nem, de joelhos postados em terra, mostrarão reverência.

$\mathrm{O}$ grande Rei perdeu a sua força.

Não mais têm os homens a língua sujeita a freios. Fica liberto um povo e fala livremente, logo que é afastado o jugo da força $\left({ }^{19}\right)$.

Sentindo-se livres da ameaça persa, alguns dos membros da Simaquia não viam necessidade de continuarem a sua aliança com Atenas, na qual consideravam existir uma hipoteca da sua Jiberdade. Começaram, por isso, a surgir no seio da confederação, tendências centrífugas, a que os Atenienses respondiam pela força, obrigando-os a manter a aliança ${ }^{20}$. Nenhuma pòlis tinha o direito de fazer secessão. A Simaquia era a fonte da força de Atenas no Egeu e, enquanto a controlasse estaria livre de problemas no mar. Em 454 o tesouro e a sede da Simaquia são transferidos de Delos para Atenas, sob pretexto da ameaça dos Bárbaros (21). Qualquer caso ou delito relacionado com a aliança passa a ser tratado na Assembleia ou julgado nos tribunais atenienses. Cada vez mais se reforça e agrava o sentimento de falta de liberdade e de

(19) Os Persas foram apresentados em 472 e Atenas vivia um momento de euforia. Vide José ribeiro Ferreira, Hélade e Helenos, p. 335. Para um comentário aos versos, p. 330.

${ }^{20}$ ) Naxos foi a primeira, logo em 471 (vide Bowra, Periclean Athens, p. 33); em 465 Tasos revolta-se, talvez em consequência da cobiça de Atenas pelas suas minas de ouro, e só dois anos depois é dominada por Címon. Vide N. G. L. Hammond, History of Greece to 322 B.C., p. 289-292; J. Pouillou, Recherches sur Vhistoire et les cultes de Thasos, Paris, 1954, p. 60-61, 93 e 106 sqq.

(21) Vide W. K. Pritchett, "The Transfer of the Delian Treasury», Historia 18 (1969) 17-21; G. D. Wilcoxon, Athens Ascendant, Ames, 1979, p. 184-185. H. B. Mattingly, «The Growth of Athenian imperialism» Historia, 12 (1963), 257-273 aponta uma data mais tardia para essa transferência. 
sujeição. Aos poucos a Simaquia perdera o seu carácter espontâneo e a intervenção de Atenas na vida dos outros Estados tornara-se progressivamente crescente, tanto a nível de relações externas como nas questões internas, sempre que considerasse afectarem os seus interesses. Estava aberta a porta para a constante interferência na vida das cidades aliadas, e estas não se encontravam em condições de resistir. Ao aceitar contribuir em dinheiro em vez de o fazer em barcos, haviam perdido a possibilidade de defesa.

O desejo de poder leva os Atenienses a endurecer o domínio sobre os aliados e a actuar com severidade, no caso de pagamentos atrasados, incompletos ou outras negligências de contribuição. Este procedimento retira-lhes a anterior popularidade. A Simaquia de Delos transformara-se num império e a maioria das cidades sentia-se nela em servidão, sem liberdades. As revoltas são assíduas, sempre reprimidas com dureza ${ }^{(22}$ ). Atenas considerava a secessão um acto de traição e de quebra do juramento da aliança. Objectava que uma série de secessões poria em perigo a organização e deixaria a Hélade sem defesa ante um possível ataque persa.

A Simaquia passa então a possuir três tipos de membros; os que, em número reduzido, contribuíam com barcos - como Quios, Samos, Lesbos - e eram os aliados propriamente ditos; os que pagavam tributos, em vez de contribuir com barcos, mas que conservavam a autonomia política e mantinham o estatuto fixado pelo tratado geral inicial; os que, sublevados e depois de novo submetidos, eram governados por tratados particulares que a cada passo thes impunham determinadas obrigações, como um governo democrático, por exemplo $\left({ }^{23}\right)$.

Num contexto destes, o desejo de libertação será um sentimento com campo propício e dele se aproveitará a propaganda de Esparta, que liderava uma outra Simaquia. Essa propaganda manifestou-se sobretudo durante a Guerra do Peloponeso que se

(22) Sobre o imperialismo ateniense vide bibliografia na nota 1 e ainda J. De Romilly, Thucydide et Vimpérialisme athénien, Paris, 1951.

(23) Vide J. B. Bu Ry, History of Greece to the Death of Alexander the Great, 4. a edição revista por R. MEIGgs, London, 1975, p. 210; P. J. RHodes, The Athenian Empire, Oxfoid (Greece and Rome 17), 1985, p. 27. 
estende de 431 a $404\left({ }^{(24)}\right.$. Então cada uma das alianças procurava chamar à sua zona de influência as cidades ligadas à outra, incentivando e apoiando as facções que defendiam regimes condizentes com os seus: Atenas promovia as democracias e Esparta as oligarquias.

De início Atenas não havia imposto sistemas democráticos a todos os seus aliados. Címon, o dirigente com mais influência na pòlis entre meados da década de 470 e 462 e filho de Milcíades, o general vencedor de Maratona, defendia um entendimento com Esparta e não era entusiasta da democracia; por isso, enquanto liderou Atenas, possivelmente permitiu que a maioria dos Estados aliados conservassem as constituições existentes. Durante a sua liderança, as oligarquias quase que eram bem recebidas.

Depois das transformações de 462/461, as coisas mudam sensivelmente. Nessa data, dá-se o ostracismo de Címon e surgem no primeiro plano da cena política Efialtes e Péricles. Os dois dirigentes consideravam que o Areópago, detentor de extensos e efectivos poderes, constituía um obstáculo ao alargamento da democracia e que, além disso, era contrário ao espírito democrático estarem tão importantes funções nas mãos de um órgão formado por membros vitalícios, por inerência. Daí as reformas, da autoria de Efialtes, que retiram ao Areópago grande parte desses poderes e prerrogativas e os transferem para a Assembleia, o Conselho dos Quinhentos e os tribunais da Helieia. A partir de então, tanto a orientação da política externa como da política interna sofrem em Atenas uma alteração significativa. A cidade envereda por uma acção mais activa de apoio ao estabelecimento de governos democráticos $\left({ }^{25}\right)$. A maioria das pequenas cidades não manifestava

(24) Esparta, na altura da criação da Simaquia de Delos, já se encontrava bem implantada no Peloponeso e liderava aí uma simaquia há quase um século. Vide Bowra, Periclean Athens, p. 36 sqq.; D. H.Leahy, «The Spartan Defeat at Orchomenus», Phoenix 12 (1958), 163-165; L. H. JefFer y, Archaic Greece Cambridge, 1976, p. 121-123 e 252-253. J. A. O. Larsen, «The Constitution of the Peloponesia League», CPh., 28 (1933) 257-276 coloca o aparecimento da Simaquia do Peloponeso corno tal em cerca de 505 a.C.

(25) Vide Hammond, A History of Greece, p. 303 sqq.; G. D. Wilcoxon, Athens' Ascendent, p. 169 sqq.; P. J. RHOdes, The Athenian Empire, p. 22-27. 
grande oposição e, possivelmente, muitas delas até teriam recebido com alegria a ajuda ateniense para implantar a democracia (26). Os Estados mais poderosos, contudo, ofereceram resistência, como Quios, Samos, Mitilene, e mantiveram até tarde os seus governos oligárquicos $\left({ }^{27}\right)$.

Atenas era uma cidade de acção, imbuída das ideias de progresso e orgulhosa do seu sistema político, que considerava o melhor e desejava doar aos outros Estados. Daí um dinamismo insaciável e um constante esforço por espalhar a democracia. Diziam os Corintios (Tue. 1. 70. 8-9), no congresso daSimaquia do Peloponeso que precede a declaração da Guerra do Peloponeso, que os Atenienses não deixavam ninguém quieto, que para eles descansar era realizar o que tinham a fazer $\left({ }^{28}\right)$. O império foi uma saída para essas energias e um chamamento a redobrar esforços. Para o ateniense a vida activa era tão louvável por si mesma que compensava qualquer objecção que pudesse levantar-se contra a dureza e a severidade implícitas nesse domínio. Péricles soube interpretar esse dinamismo e incitou os seus concidadãos a servirem de paradigma e exemplo para os outros - um ideal que cativou as imaginações. «Escola da Hélade», Atenas era além disso uma forte potência militar. Em consequência disso, na opinião de Péricles, estava apta a governar outras cidades, e tinha até legitimidade de o fazer (Tue. 2.41.3), já que realiza pelos outros o que mais nenhuma potência pode fazer: oferecia-lhes uma vida mais gloriosa e ampla, de maior liberdade, em troca de um pouco de diminuição da

(26) Cf. Píndaro, 01. 7. Vide B. L. Gildersleeve, Pindar: The olympian and Pythian Odes, New York, 1885, repr. 1979, p. 182-183; D. W. B RADEEN, «The Popularity of the Athenian Empire», Historia 9 (1960), 257-269; RноDes, The Athenian Empire, p. 36-42.

(27) Quios mantém esse governo até 412. Samos e Mitilene - oligarquias até 440/439 e 428, respectivamente — perdem nessa altura tal regime, porque, revoltosas, são dominadas, drasticamente castigadas e obrigadas a adoptar um regime democrático (cf. Aristóteles, AP. 24.2). Sobre o assunto vide MeIGGS, The Athenian Empire, p. 188-192, 311-317 e 358-363; T. J. QuinN Athens and Samos, Lesbos and Chios. 478-404 b.C, Manchestei, 1981. Para, Samos vide G. Shiplley, A History of Samos 800-188 b.C., Oxford, 1987, p. 113 sqq.

(28) Sobre o passo de Tucidides vide Gомме, HCT, I, p. 231-232, ad. loc. 
independência. Se nem todos os aliados aceitaram de bom grado tais doutrinas, muitos fizeram-no e demonstraram-no com actos $\left({ }^{29}\right)$.

Considerado por Tucídides uma «tirania» (2.63.2), o império de Atenas sobre as outras cidades da Simaquia de Delos teve esse carácter, sem dúvida, se se entender por tal apenas o domínio de um Estado por outro. De modo geral não se tratou, porém, de um poder excessivo. É mesmo curioso observar, como nota Forrest, que esse domínio, considerado tão duro e impopular por Tucídides, a muitos dos subjugados pareceu preferível à «liberdade» oferecida por Esparta ou por outros adversários de Atenas ( $\left.{ }^{30}\right)$. No decurso da expedição à Sicília, quando se adivinhava a derrota iminente da frota ateniense, a maior parte dos contingentes das cidades aliadas preferiu uma morte quase certa e ficar a seu lado à oferta de Siracusa que lhes prometia a libertação e a salvação, se desertassem ( ${ }^{31}$ ). Que esse domínio tenha sido bem aceite - ou pelo menos tolerado - mostra que, no seu conjunto, era benéfico, eficaz e mesmo proveitoso.

Atenas deu às massas populares a noção dos seus direitos e da sua dignidade, pelos quais estavam dispostos a lutar, não só contra os inimigos imediatos no interior, mas também contra Esparta ou outros opositores que externamente encarnassem os sentimentos que rejeitavam. As classes inferiores, nos Estados pequenos, não possuíam força suficiente para afastar as oligarquias locais ou, depois, impedir que elas se refizessem. Preferiam por isso, a cada passo, entrar como súbditos no Império de Atenas, para beneficiar do apoio dela à democracia, a continuar com independência política, mas sem democracia interna ( $\left.{ }^{32}\right)$.

É estranho, pois, que Tucídides declare ser o império ateniense na Simaquia de Delos motivo de ódio e constituir para Atenas um constante perigo possível. E tais afirmações tanto as encontramos

(29) Vide Bowra, Periclean Athens, p. 126.

(30) La naissance, p. 39.

(31) Cf. Tucídides 7.67 e, sobretudo, 82.1. Vide Meiggs, The Athenian Empire, p. 347-348.

(32) Vide G. E. M. Ste Croix, «The Character of the Athenian Empire», Historia, 3 (1954), 1-41 e Origins of Peloponnesian War, p. 34-42; FINLEY, Democracy, p. 54; Bow Ra,Periclean Athens, p. 97-98. 
na boca dos membros da Simaquia do Peloponeso - o rei Arquidamo, por exemplo, fala do ódio de toda a Grécia contra Atenas (2. 11. 2) - como na de Atenienses e até na de Péricles. Este, ao discursar perante o povo descontente nos primeiros anos da Guerra, aponta-lhes o perigo derivado do ódio que haviam concitado com a consolidação do império (2. 63. 2). Em 427, na altura da revolta de Mitilene, na Assembleia que decide sobre os destinos da cidade, Gléon lembra aos Atenienses que o império é uma tirania e que os súbditos a sofrem de mau grado, que a submissão só resulta do ascendente obtido pela força (3. 37. 2). A insistência de Tucídides parece mais uma posição de facção do que realidade objectiva $\left({ }^{33}\right)$.

Havia, é certo, entre os aliados uma importante oposição, mas ela vinha de modo geral dos aristocratas dessas cidades que viam em Atenas - que apoiava as democracias e incentivava a participação dos cidadãos mais pobres no governo local — um inimigo real ou possível e preferiam quem favorecesse as oligarquias locais. Por isso, sempre que agarravam uma oportunidade, sublevavam-se e, de modo geral, abandonavam a Simaquia de Delos, para aderir à do Peloponeso. Assim acontece na Eubeia, em 447 ; em Samos, em 440/439; em Mitilene, em 428. Em nenhum dos casos, porém, encontramos levantamentos à escala de toda a pòlis. De modo geral, eram os nobres descontentes que the davam forma e a lideravam ${ }^{(34)}$.

Manter um império em tais circunstâncias, com secessões e revoltas constantes, implica gastos substanciais e uma frota permanente, na qual eram peças chave, como vimos, os tetas $\left.{ }^{3 \mathrm{~S}}\right)$.

O império foi, no entanto, também uma peça importante para o funcionamento e a institucionalização do sistema democrático e trouxe - observa-o Finley - vantagens e ganhos materiais que superavam os gastos. Além de um considerável número de outras vantagens secundárias, atraía, proveniente dos impostos das cidades aliadas, um rendimento anual um pouco superior ao total das

(33) Vide P. J. Rhodes, The Athenian Empire, pp. 36-37; Meiggs, The Athenian Empire, p. 375 sqq.

(34) Vide Bowra, Peridean Athens, p. 96-97.

(35) Vide supra, p. 39. 
receitas públicas derivadas dos recursos internos; proporcionava uma frota influente e forte, a mais poderosa do Egeu e talvez do Mediterrâneo; facultava segurança para as importações de trigo que eram vitais a Atenas $\left({ }^{36}\right)$. Foi uma fonte de fundos que possibilitou a reconstrução dos templos e outros edifícios públicos - caso do santuário de Eleusis —-, destruídos durante a invasão de Xerxes, e a construção dos esplêndidos monumentos da Acrópole. Essas obras, além de se tornarem uma fonte de emprego para muitos assalariados que, de outro modo, poderiam ter constituído um foco de agitação e de revolta, aparecem também - e teriam sido assim concebidas - como um símbolo da grandeza de Atenas e do papel que os seus dirigentes e artistas consideravam ser o da cidade na Hélade $\left({ }^{37}\right)$. Por trás dessas obras estava a ideia de que Atenas tinha que inspirar à Grécia uma unidade espiritual mais forte.

Em termos de interesses materiais, se as vantagens e benefícios dos ricos não eram significativos nem mensuráveis, os cidadãos pobres, ou o dêmos, lucravam com o império - para me servir dos termos de Finley- «de forma directa, tangível e substancial»: assegurava a subsistência aos remadores da frota que se sentiam, além disso, governantes do mundo grego; permitia concedersalários a quem participasse em cargos públicos e desse modo possibilitava que todos os cidadãos acedessem a esses cargos, fossem quais fossem os seus recursos económicos; trazia ganhos a certos grupos, como os construtores de barcos e os carpinteiros da marinha; ajudava a garantir, pelo controlo dos mares, a afluência regular dos cereais e a consequente manutenção dos preços baixos; permitia conceder a certo número de cidadãos pobres, talvez uns 20000 , parcelas das terras confiscadas nas cidades revoltosas e depois dominadas - as cleruquias $\left.{ }^{38}\right)$.

(36) Finley, Democracy, p. 43-44.

(37) Vide Bow r a, Periclean Athens, p. 114-118.

(38) Democracy, p. 44-48. Atenas, como era prática geral de outras cidades, se conseguia dominar os revoltosos, de modo geral matava a população do sexo masculino em idade de combater e escravizava as mulheres e crianças (e. g., Tue. 5.116.2-3). A região colonizava-a com cidadãos atenienses pobres. São as cleruquias, colónias do tipo extensão territorial da metrópole que se

Conimbriga $_{i} 28$ (1989), 33-51 
Isto permitia minorar as carências e evitar o agravamento excessivo dos conflitos sociais. Desse modo, até aos fins do século v, praticamente não assistimos em Atenas a guerras civis ${ }^{(39}$ ).

O império que a cidade exerce no mar Egeu parece ser elemento decisivo no seu equilíbrio social. Deu um grande desenvolvimento ao Pireu e fez crescer o número de metecos $\left({ }^{40}\right)$. Aristóteles afirma mesmo que ele fazia viver 20000 homens e o «Velho Oligarca» na República dos Atenienses 1. 10-11 põe em realce os laços estreitos que uniam a política imperialista ateniense e a sua força naval ao próprio regime $\left({ }^{41}\right)$.

Sem o império e sem os recursos que dele provinham, o sistema plenamente democrático da segunda metade do século $\mathrm{v}$ não teria sido introduzido ou pelo menos não se teria mantido. Sem tais fundos, os rendimentos de Atenas não seriam muitos. Ora, se os encargos financeiros e militares - observa-o Finley - pesassem sobre os ricos não surpreenderia que estes - como acontecia em outras democracias que, desde meados do século vi, começaram a surgir em outras cidades gregas - reivindicassem o direito de governar por meio de uma qualquer constituição mais ou menos oligárquica ${ }^{42}$. Se mais tarde, nos fins do século $\mathrm{v}$, o império foi destruído, nessa altura já o sistema estava fortemente consolidado e ninguém o conseguiu modificar, apesar das várias tentativas empreendidas nesse sentido e apesar das dificuldades financeiras ao longo do século iv.

podem aproximar das modernas, mas que não correspondem ao tipo de colonização grega mais usual. Vide Gl. Mosse, La colonisation dans VAntiquité, Paris, 1970, p. 72-81; Ph. Gauthier, «Les clérouques de Lesbos et la colonisation athénienne au Ve. siècle», REG, 79 (1966), p. 64-88 ; A. J. Graнa м, Colony and Mother City in Ancient Greece, Manchester, 1964, p. 166-210.

(39) Vide Finle y, Democracy, p.48-49.

$\left({ }^{40}\right)$ Vide Cl. Moss e, Histoire d'une Démocratie: Athènes, p. 52-53.

(41) Aristóteles, ^4P. 24.3. Sobre o passo vide P. J. Rhodes, Comm. on Arist., AP., p. 301 sqq. ad. loc.

Um exemplo de democracia com uma constituição ainda de características oligárquicas é o de Quios em meados do século VI. Vide V. E h R E n B R g, «Origins of Democracy», Historia 1 (1950), 538; R. MEIGGS and D. LEwis, A Selection of Greek Historical Inscriptions to the End of the Fifth Century B.C., Oxford 1969, repr. 1980, p. 14-17.

(42) Vide Finley, Democracy, p. 50. 
Deste modo se verifica que, subjacentes aos conhecidos acontecimentos históricos das Guerras Pérsicas, da criação da Simaquia de Delos e da consequente sistematização do império ateniense, se detectam interrelações entre sistema político e situação económica e social, determinantes para o estabelecimento definitivo de uma forma de governo - o da democracia ateniense - que era também, ao mesmo tempo, um estilo de vida. 